\title{
Impacts of Vaccination on Hepatitis B Viral Infections in Korea over a 25-Year Period
}

\author{
Neung Hwa Park ${ }^{a}$ Young-Hwa Chung ${ }^{b}$ Hyo-Suk Lee ${ }^{c}$ \\ a Department of Internal Medicine and Biomedical Research Center, Ulsan University Hospital, University of Ulsan \\ College of Medicine, and bepartment of Internal Medicine, Asan Medical Center, University of Ulsan College of \\ Medicine, Ulsan, and 'Department of Internal Medicine and Liver Research Institute, Seoul National University \\ College of Medicine, Seoul, Korea
}

\section{Key Words}

Epidemiology $\cdot$ Hepatitis B vaccine $\cdot$ Hepatitis B virus • Korea

\begin{abstract}
Background: Hepatitis B virus (HBV) vaccination has effectively reduced the acute and chronic infection rates in recent years. Since 1983, HBV vaccination has been recommended for all neonates in Korea. Methods: This article reviews the impacts of HBV vaccination throughout the past 25 years in Korea. Before the introduction of the HBV vaccination program, approximately $8 \%$ of the general Korean population tested positive for hepatitis B virus surface antigen (HBsAg). Results: The percentage of vaccinated infants has surpassed 98.9\% since 1990. The HBsAg carrier rate in the general population decreased to $3.7 \%$ in 2007. In particular, the prevalence of HBsAg decreased to $0.44 \%$ in teenagers and to $0.2 \%$ in children younger than 10 years. In addition, administration of the HBV vaccine may have reduced the risk of hepatocellular carcinoma among adults. Despite the administration of hepatitis B immunoglobulin and the HBV vaccine to children with HBsAg-positive mothers, the failure rate of HBV immunoprophylaxis was $4.2 \%$ in 2008. In Korea, there have been no reported cases of HBV surface gene variants
\end{abstract}

such as G145R. Conclusions: The prevalence of HBV carriers in Korea was markedly reduced after the introduction of the universal HBV vaccination program. Korea is now classified as an area of intermediate endemicity for HBV.

Copyright $\odot 2010$ S. Karger AG, Basel

\section{Introduction}

Hepatitis B virus (HBV) infection is a serious public health problem worldwide and a major cause of chronic hepatitis, cirrhosis, and hepatocellular carcinoma (HCC) [1]. At least 2 billion people, or one third of the world's population, have been infected with HBV and an estimated 1 million people die each year from acute and chronic sequelae secondary to HBV infection [2]. In addition, more than 400 million people, or $6 \%$ of the world's population, are chronic carriers of HBV. Approximately 4.5 million new cases of HBV infection occur worldwide each year, and one fourth of these cases progress to liver disease [3]. There is a marked difference in the geographic distribution of carriers, ranging from $10-20 \%$ in SouthEast Asia and Sub-Saharan Africa to less than $1 \%$ in Northern Europe and America [1, 4]. Approximately 75\% of chronic carriers live in Asia and the Western Pacific [1,

\section{KARGER}

Fax +4161306 1234 E-Mail karger@karger.ch www.karger.com (c) 2010 S. Karger AG, Basel

0300-5526/10/0531-0020\$26.00/0

Accessible online at:

www.karger.com/int
Young-Hwa Chung, MD

Asan Medical Center, University of Ulsan College of Medicine

388-1 Pungnap-2 dong

Songpa-gu, Seoul 138-736 (Korea)

Tel. +82 23010 3184, Fax +82 24760824 , E-Mail yhchung@ amc.seoul.kr 
4]. In low endemic areas, most HBV infections are acquired via horizontal transmission among adolescents and young adults. Conversely, in areas of high endemicity, the most common route of transmission is perinatal and the infection is often acquired during the preschool years $[2,4]$. The risk of becoming an HBV carrier is $90 \%$ in cases of perinatal infections, between 25 and 30\% for infected infants and children under 5 years of age, and less than $10 \%$ for infected adults $[2,4]$. More than $25 \%$ of infants and older children who acquire HBV infection will eventually develop HBV-related HCC or cirrhosis. Adults who have had chronic HBV infection since childhood develop HCC at a rate of $5 \%$ per decade, which is 100 to 300 times the rate among uninfected persons $[1,4]$. In Korea, HCC is both the third most common and the third most deadly cancer. The age-standardized mortality rate for HCC is 33.9 per 100,000 men and 10.9 per 100,000 women. The annual death rates from HCC were 21.4 per 100,000 persons in 1996 and 22.4 per 100,000 persons in $2006[5,6]$. The number of deaths from liver cancer increased from approximately 5,789 in 1983 to 9,966 in 1994 , then remained steady at 9,500 per 100,000 persons in 2006 [7, 8]. With regards to the etiological agents of HCC, approximately $65-75 \%$ of patients test positive for hepatitis B virus surface antigen (HBsAg), and $10-20 \%$ of patients test positive for antibodies to HCV (anti-HCV) [9, 10]. Because less than 10\% of HCC cases are non-B or non- $\mathrm{C}$, surveillance of hepatitis carriers is the most important tool for the prevention of HCC in Korea. Although current antiviral treatments using interferons or nucleoside/nucleotide analogs are effective against chronic HBV, chronic carriage of the virus is more difficult to eliminate. Considering that most HBV infections in Korea occur vertically, universal infant vaccination is the key to the elimination and subsequent eradication of HBV. Therefore, the combined efforts of vaccination and effective treatment regimens may eventually lead to the eradication of HBV.

The first HBV vaccine, derived from human carrier plasma, was approved for use in the United States in 1981. In 1991, the WHO recommended that all countries implement a policy of universal HBV vaccination by 1997 [11]. Most countries have incorporated universal HBV vaccination into their national infant immunization programs. The estimated global coverage rate of infant HBV vaccination increased from less than $1 \%$ in 1990 to $30 \%$ in 2000, and from nearly 50\% in 2004 to $69 \%$ in 2008 [12]. As of 2008,177 of the 193 WHO member states $(92 \%)$ had initiated HBV vaccination programs [13]. This program reduced not only the rate of persistent infection and the total prevalence of $\mathrm{HBV}$ in the younger generation but also the occurrence of childhood HCC and fulminant hepatitis [14]. In Korea, hepatitis B has significantly declined in the past decades as a result of the HBV vaccination program and the introduction of other public health measures such as use of universal precautions in medical settings and blood screening tests. Thus, this article reviews the impacts of $\mathrm{HBV}$ vaccination in Korea over the past 25 years.

\section{Strategy for the Prevention of HBV Infection in Korea}

Korea was classified as an area of high endemicity before the implementation of the universal HBV vaccination program. The first domestic plasma-derived HBV vaccine became available in Korea in 1982, and HBV vaccination has been recommended for all neonates since 1983. The first national HBV vaccination program began in 1985 for newborn infants whose mothers were HBsAg carriers. A national $\mathrm{HBV}$ vaccination program for schoolaged children was launched in Korea in 1988, and HBV vaccination was incorporated into the national vaccination guidelines in 1991. In 1995, Korea began universally vaccinating newborn infants to prevent the perinatal transmission of HBV. A national program to prevent the vertical transmission of HBV was launched in 2002 [15]. In Korea, most cases of HBV infection occur when the virus is transmitted from carrier mothers to infants during the perinatal period, and from other horizontal sources to infants and children. Over the past 25 years, Korea has adopted a series of strategies to eliminate HBV infection and prevent transmission of the virus [16]. These strategies involve the universal vaccination of infants and adolescents, and the screening of all pregnant women for HBsAg to prevent perinatal HBV transmission. Since 1983, HBV vaccination at 0,1 and 2 months or at 0,1 and 6 months after birth has been compulsory for all neonates born in Korea. To prevent perinatal transmission, infants born to HBsAg-positive mothers and mothers of unknown HBsAg status receive the HBV vaccine and hepatitis B immunoglobulin (HBIG) within $24 \mathrm{~h}$ of birth. The $\mathrm{HBV}$ vaccine is also recommended for high-risk groups (e.g. homosexual men, health-care workers, drug users, people with multiple sexual partners, people who live with chronically infected persons, chronic hemodialysis patients, HIV-infected patients and other immunocompromised persons). 


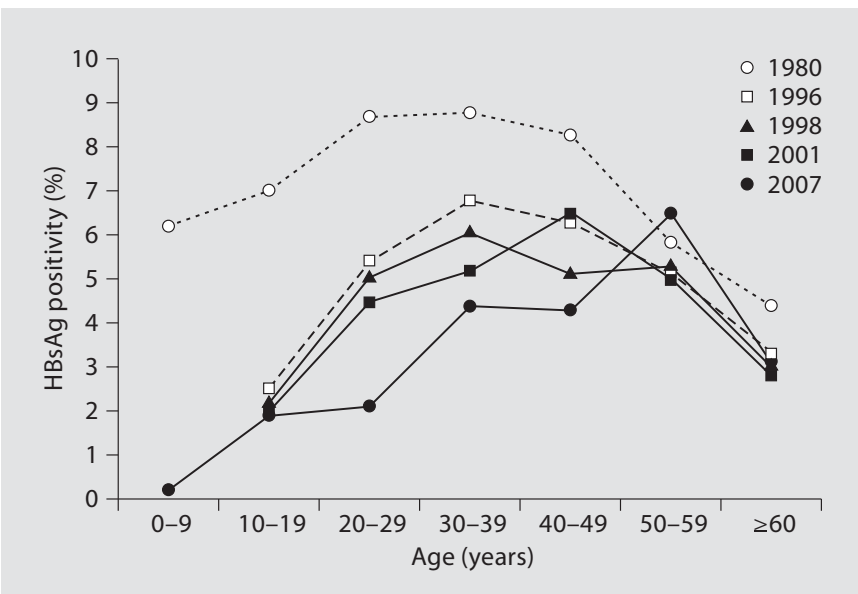

Fig. 1. Changes in the prevalence of HBV carriers over the past 25 years, after the introduction of HBV vaccine in Korea. Since 1983, $\mathrm{HBV}$ vaccination has been recommended for all neonates in Korea. Data were adapted from [22, 27].

In Korea, approximately $79.7 \%$ of neonates born after 1983 and $98.9 \%$ of neonates born after 1990 received the HBV vaccine [17]. However, a study [18] of 2,072 elementary school students in 1993 revealed that only $69.8 \%$ of the children had received all 3 doses of the HBV vaccination schedule. In general, a protective antibody response occurs after the first dose in $30-50 \%$ of healthy adults aged 40 years or younger. This protective response occurs in $75 \%$ of healthy adults after the second dose, and in more than $90 \%$ of healthy adults after the third dose [14]. Data obtained from a Korean survey of national immunity in 2007 revealed that after the completion of the 3dose HBV vaccination regimen, approximately $95 \%$ of individuals exhibited protective concentrations of the anti-HBs antibody [19].

\section{Impacts of HBV Vaccination in Korea over a 25-Year Period}

\section{Changes in the Prevalence of Chronic HBV Carriers}

According to several studies published in the $1980 \mathrm{~s}$ and early 1990s, the prevalence of chronic HBV carriage ranged from $8-10 \%$ before the introduction of the HBV vaccine (fig. 1) [20-22]. In 1990, Oh and Joung [23] reported that the prevalence of HBsAg positivity was 5.27\% among 173,342 school students (aged 7-18 years) born before the vaccination program was introduced. Kim et al. [24] conducted a study of 498,206 male army draftees between 1993 and 1999 to evaluate HBV infection. The majority of the draftees were born before the launch of the universal vaccination program and were 20 years old. Thus, the draftees received the HBV vaccine as schoolaged children rather than as infants. Among these draftees, positivity of HBsAg gradually decreased from 5.8\% in 1993 to $4.3 \%$ in 1999. Jang et al. [25] also reported that the overall prevalence of HBsAg among more than 600,000 subjects older than 6 years was $8.3 \%$ in 1995 , $4.8 \%$ in $1996,3.4 \%$ in 1997 and 1998, and 2.6\% in 1999. Subgroup analysis revealed that the rates of HBsAg carriage among subjects aged $6-19$ years were $8.2 \%$ in 1995 , $3.9 \%$ in $1996,2.1 \%$ in $1997,2.6 \%$ in 1998 and $1.3 \%$ in 1999 . Hence, the rate of HBsAg carriage declined from $8.2 \%$ in 1995 to $1.3 \%$ in 1999. Most of the subjects were born after the introduction of the universal vaccination program. However, the rates of HBsAg carriage among subjects older than 20 years during the same years were 8.9, 6.4, $5.9,5.4$ and $5.4 \%$, respectively, and the rates decreased from $8.9 \%$ in 1995 to $5.4 \%$ in 1999 . For all years, the rates of HBsAg carriage were significantly lower among subjects aged 6-19 years than among subjects older than 20 years. Jang et al. [26] also reported that between 1997 and 1999, the prevalence of HBsAg among 120,220 school students (age range 7-18 years; born between 1981 and 1992) was $2.5 \%$. The rate of HBsAg carriage among elementary school students (born between 1987 and 1992) was 1.4\%, which was significantly lower than the rates of $\mathrm{HBsAg}$ carriage among junior high school students (3.2\%; born between 1982 and 1986) and senior high school students (3.4\%; born between 1981 and 1983). During the same years, the overall rate of HBsAg carriage decreased significantly from 2.8 to $1.9 \%$. Although many epidemiological studies have assessed HBV infection in Korea, most of the studies were based on unrepresentative or small populations from selected communities. The Korean Ministry for Health, Welfare and Family Affairs performed the National Health and Nutrition Survey of 4 cohorts, aged 10 years or older, in 1998, 2001, 2005 and 2007 to investigate the epidemiological characteristics of $\mathrm{HBV}$ infection in Korea [27]. As the survey was based on a representative sample of the entire nation and used a stratified multistage probability sampling design, these data provide a comprehensive picture of the distribution of HBV in Korea. Data obtained from the first National Health and Nutrition Survey in 1998 revealed that the rates of HBsAg seropositivity in children aged 10 years and older were $5.1 \%$ in males and $4.1 \%$ in females [28]. Among children and adolescents younger than 20 years, the seropositivity rates were $2.1 \%$ in males and $2.7 \%$ in 
females. The peak ages for seropositivity were 20-29 years in males and 30-39 years in females, after which time the rates remained the same until the subjects reached 50-59 years. The rates then decreased in both males and females. According to these nationwide surveys, the prevalence of HBsAg positivity in persons older than 10 years decreased from $4.6 \%$ in 1998 to $3.7 \%$ in 2007 . The rate of HBsAg carriage among subjects between 10 and 18 years old declined from $2.2 \%$ in 1998 to $0.2 \%$ in 2005 [27]. A 2007 survey of national immunity conducted by the Korea Centers for Disease Control showed the prevalence of HBsAg was $0.2 \%$ in children aged $4-6$ years [19]. Similarly, the Korean Ministry of Education, Science and Technology conducted student health examinations in 2006 to investigate the epidemiological characteristics of $\mathrm{HBV}$ infection in Korea. The prevalence of HBV infection among junior high school students was $0.44 \%$ [29]. Data obtained from the fourth National Health and $\mathrm{Nu}$ trition Survey of Korea in 2007 revealed that the prevalence of HBsAg was 3.7\% among males and females aged 10 years and older [27]. The prevalence of HBsAg was higher in men (4.3\%) than in women (3.2\%), and the total number of HBV carriers was estimated to be more than $1,800,000$ persons in 2007 [27]. A sustained decline of $\mathrm{HBV}$ infection is expected in the future, whereupon the prevalence of HBV infection in Korea will eventually be as low as that in Western countries.

\section{Changes in HBV Surface Antibody Positivity}

The rates of HBV surface antibody (anti-HBs) in 332,780 students aged $6-17$ years increased sharply, from 21.7\% in 1988 to 54.1\% in 1993 [30]. In 1993, Lee et al. [18] examined the prevalence of anti-HBs among 2,072 elementary school students, and found that the anti-HBs seropositive rate was $88.9 \%$ among children aged $6-7$ years and $75.8 \%$ among children aged $12-13$ years. Jang et al. [26] also reported in the late 1990s that the prevalence of anti-HBs among 120,220 students aged 7-18 years was 47.4\%. In 1998, the first National Health and Nutrition Survey found that the anti-HBs seropositive rate was $57.0 \%$ in males and $58.9 \%$ in females [28]. An et al. [31] reported that, between 2003 and 2005, the rates of antiHBs by age were $78.6 \%$ for infants aged $6-12$ months, $62.7 \%$ for children aged $1-3$ years, $51.9 \%$ for children aged $4-6$ years, $49.5 \%$ for children aged $7-12$ years, $63.4 \%$ for adolescents aged $13-15$ years and $72.2 \%$ for adolescents aged 16-18 years. A 2007 survey of national immunity conducted by the Korea Centers for Disease Control revealed that the anti-HBs prevalence was $56.0 \%$ in children aged $4-6$ years [19].

Impacts of HBV Vaccination in Korea

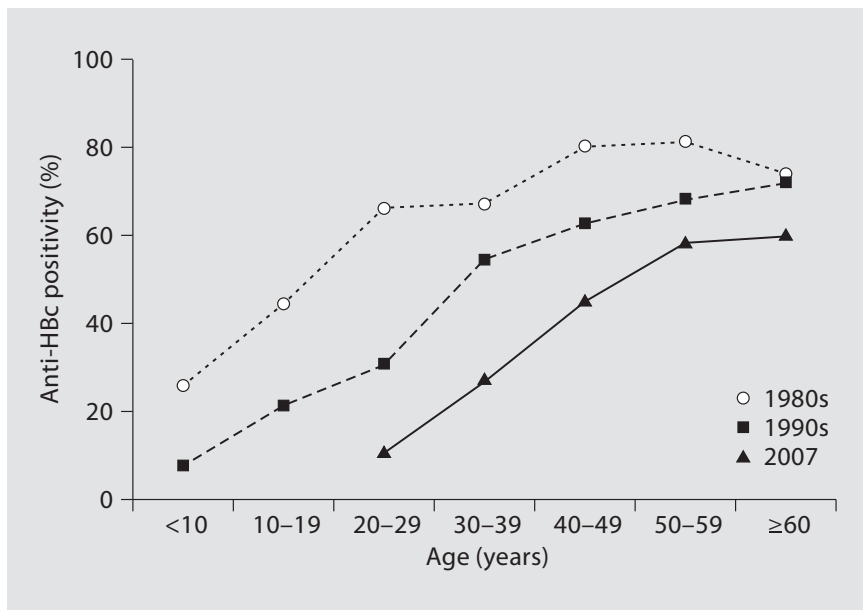

Fig. 2. Changes in anti-HBc positivity over the past 25 years, after the introduction of HBV vaccine in Korea. Since 1983, HBV vaccination has been recommended for all neonates in Korea. Data were adapted from $[32,33]$.

\section{Changes in HBV Core Antibody Positivity}

During the 1980 s, $11 \%$ of newborn babies in Korea became infected with HBV during the perinatal period. Thereafter, the prevalence of HBV core antibody (anti$\mathrm{HBc}$ ) increased with increasing age. The anti-HBc positivity rate was nearly $30 \%$ among children younger than 10 years. Among adults in their forties, the infection rate reached approximately $70 \%$ (fig. 2) [32]. After the introduction of the vaccine program, Lee et al. [18] reported that the anti-HBc seropositive rate in 1993 was $7.1 \%$ among children aged 6-7 years and $15.6 \%$ among children aged $12-13$ years. During the late 2000 s, the prevalence of anti-HBc decreased with decreasing age and was $10.6 \%$ in adults younger than 30 years. These data may reflect the effects of universal HBV vaccination in Korea. The proportion of anti-HBc was highest in adults aged $50-59$ years (52.4\%) and decreased with decreasing age [33].

\section{Changes in the Epidemiologic Profile of Acute Hepatitis $B$}

The epidemiologic profile of acute HBV infection in Korea continues to change in response to the universal $\mathrm{HBV}$ vaccination program. Concerning the etiology of acute viral infection during the early 1990s, the prevalence rates of acute viral hepatitis $\mathrm{A}, \mathrm{B}, \mathrm{D}$ and non- $\mathrm{A} /$ non-B were $3.4,60.3,0.9$ and $35.3 \%$, respectively, with HBV infection being the most common cause [34]. According to data reported between 2006 and 2008 [35], the majority (70\%) of 


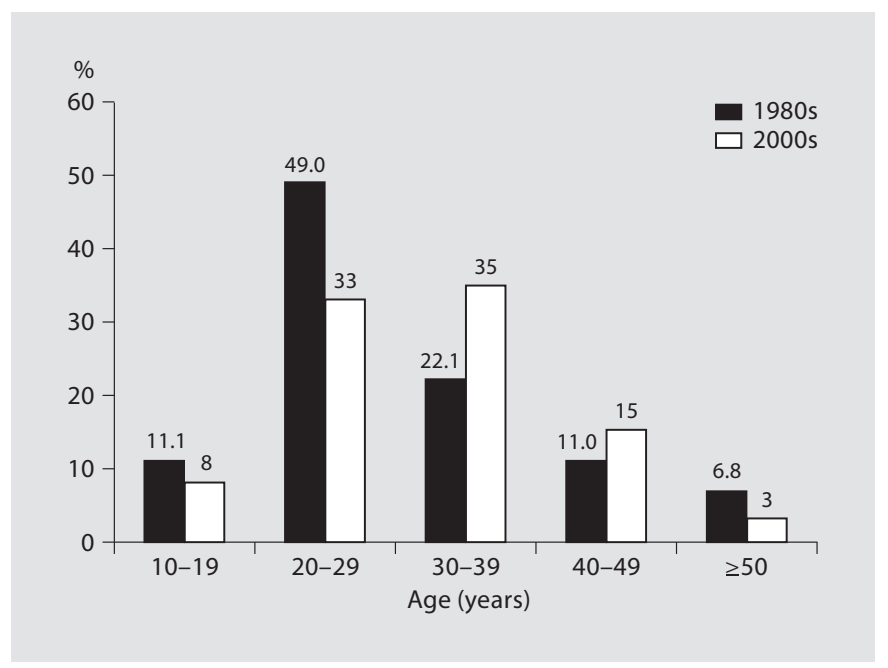

Fig. 3. Age distribution of acute hepatitis B in the 1980s and 2000s. The peak age was 20-29 years in the 1980s, and 30-39 years in 2000s. Data were adapted from [37].

cases of acute viral infection were caused by the hepatitis A virus, while $\mathrm{HBV}$ accounted for only $5 \%$. Therefore, the incidence of acute hepatitis B dramatically declined after the introduction of the HBV vaccination program. According to the 2008 Guidebook of the Hepatitis B Vertical Transmission Prevention Program of the Korean Ministry for Health, Welfare and Family Affairs [36], the incidence of acute hepatitis $B$ in adult males older than 30 years was 17 per 100,000 . After the implementation of the $\mathrm{HBV}$ vaccination program, the peak age of acute hepatitis $B$ has also changed (fig. 3). Cases of acute hepatitis B peak in adults aged 20-29 years. The majority of acute hepatitis B cases in the early 1980s occurred in people aged 10-29 years $(60.0 \%)$. The decline in the incidence of acute hepatitis B after the introduction of the HBV vaccination program was more striking in adults aged $10-29$ years, who were born after the introduction of $\mathrm{HBV}$ vaccination. On the other hand, the incidence of acute hepatitis B in the early 2000s was highest among adults aged 30-39 years, who were born before the introduction of the HBV vaccination program [37]. Other cohort studies from Korea also demonstrated that HBV infection occurs commonly in adulthood $[38,39]$. Thus, HBV transmission may still occur in unvaccinated and uninfected adults, and HBV vaccination is able to prevent the spread of infection within the family and as a result of direct contacts during adulthood. Therefore, an adult without a complete set of previous vaccinations should be given 'catch-up' HBV vaccinations to prevent acute $\mathrm{HBV}$ infection.

\section{Changes in the Incidence of HCC}

A Taiwanese study demonstrated a decline in the incidence of HCC in children after the implementation of the universal hepatitis B vaccination [40]. Importantly, a large-scale cohort study [41] performed in Korea reported that HBV vaccination protected against the development of HCC in adult men. With regards to the incidence among unvaccinated and uninfected people (table 1), the relative risks of HCC among the chronically infected and among the unvaccinated and infected were 18.1 (95\% CI $14.2-22.9)$ and 0.34 (95\% CI 0.19-0.60), respectively. The relative risk of HCC among the vaccinated group was 0.58 (95\% CI 0.31-1.09). That is, the incidence of HCC was lower in the vaccinated group than in the unvaccinated group. This study suggests that $\mathrm{HBV}$ vaccination significantly decreases the incidence of HCC, even in adulthood. However, the follow-up period was only 4 years, and HCC requires several decades to evolve from the HBV carrier state. Thus, long-term follow-up studies will be needed to verify these findings. Along with a decrease in HBsAg carrier status, HCC development is expected to decrease in the near future.

\section{Immunoprophylaxis Failure}

Epidemiological studies in the 1980s found that $6.57 \%$ of pregnant women in Korea were HBsAg positive [22]. The prevalence of HBsAg in pregnant women was $4.1 \%$ in $1990,3.4 \%$ in 1995 and 3.3\% in 2002 [42]. A survey conducted by the Korea Centers for Disease Control and Prevention [43] also reported that the prevalence of HBs$\mathrm{Ag}$ in pregnant women was $3.4 \%$ in 1995 and $3.2 \%$ in 2006. HBV e antigen ( $\mathrm{HBeAg}$ ) positivity was found in $53.1 \%$ of HBsAg-positive mothers and in $50.7 \%$ of their HBV-infected newborns [32]. During the 1980s, 11\% of newborn babies in Korea were infected with HBV via maternal transmission during the perinatal period [32]. In particular, the vast majority (i.e. 65-93\%) of unvaccinated infants born to HBeAg-positive mothers became infected $[44,45]$. Chung et al. [46] also reported that $45 \%$ of HBsAg-positive mothers were $\mathrm{HBeAg}$ positive. Between 40 and $80 \%$ of all mothers of HBsAg-positive children are HBsAg positive. The HBsAg carrier rate for siblings ranges from 33 to $67 \%[47,48]$. In addition, the vertical transmission rate was $48.3 \%$ in children born to HBsAg-positive mothers. In contrast, the paternal transmission rate was low, and $21.4 \%$ of the children had HBsAg-positive fathers [47]. Another study also examined the rates of perinatal transmission between siblings with HBsAg- 
Table 1. Association between $\mathrm{HBV}$ vaccination and risk of $\mathrm{HCC}$ among male adults

\begin{tabular}{lcl}
\hline Serological profiles and vaccination status & $\begin{array}{l}\text { Incidence } \\
\text { rate of HCC }\end{array}$ & $\begin{array}{l}\text { Relative risk of HCC } \\
\text { (95\% CI) }\end{array}$ \\
\hline HBsAg- and anti-HBs- & 13.7 & 1.0 \\
$\quad$ non-vaccinee (the unvaccinated and uninfected group) & 8.0 & $0.58(0.31-1.09)$ \\
$\quad$ vaccinee (the vaccinated group) & 4.4 & $0.34(0.19-0.60)$ \\
HBsAg- and anti-HBs+ (the unvaccinated and infected group) & 215.9 & $18.1(14.2-22.9)$ \\
HBsAg+ and anti-HBs- (the chronically infected group) & \\
\hline
\end{tabular}

Data retrieved from Lee et al. [41].

Table 2. Overall prevalence of HBV infection in siblings by age and parental HBsAg status

\begin{tabular}{|c|c|c|c|}
\hline & $>20$ years old & $10-19$ years old & $<10$ years old \\
\hline \multicolumn{4}{|c|}{$\mathrm{HBV}$ prevalence in siblings by HBsAg-positive } \\
\hline parent & $24.2 \%(136 / 561)$ & $12.8 \%(44 / 345)$ & $2.1 \%(4 / 192)$ \\
\hline & & & \\
\hline \multicolumn{4}{|c|}{$\begin{array}{l}\text { Adolescents older than } 20 \text { years were born before any system- } \\
\text { atic HBV vaccination began, children younger than } 10 \text { years old } \\
\text { were born after Korea's universal vaccination program for new- } \\
\text { born infants had been implemented, and those between } 10 \text { and } 19 \\
\text { years old were born in an intermediate phase where certain groups } \\
\text { received vaccination. Data taken from Kong et al. [49]. }\end{array}$} \\
\hline
\end{tabular}

positive parents (table 2). The overall prevalence of $\mathrm{HBV}$ infection in siblings by age and parental HBsAg status was similar to those of the past reports above.

Before the introduction of the HBV vaccine, nearly 90\% of infants born to HBeAg-positive mothers were infected at birth $[44,45]$. By administering HBIG and the $\mathrm{HBV}$ vaccine to all neonates born from $\mathrm{HBsAg}$-positive mothers, $88-95 \%$ of all cases of perinatal transmission of HBV could be eliminated $[44,45]$. However, despite the adequate administration of $\mathrm{HBIG}$ and the $\mathrm{HBV}$ vaccine at birth, about $5-10 \%$ of cases of perinatal transmission of HBV could not be completely prevented [50, 51]. Although the cause of prophylaxis failure is still unclear, high levels of maternal viremia and intrauterine infections probably play a role [50-53]. According to a 2004 report by the Korea Centers for Disease Control and Prevention [54], vertical transmission in infants was uniquely associated with the mother's $\mathrm{HBe} A g$ seropositivity and HBV DNA levels. HBsAg-positive rates in 854 infants according to the HBeAg status and HBV DNA levels of
Table 3. Vaccine failure rates in infants according to HBeAg status and HBV DNA levels of HBsAg-positive mothers

\begin{tabular}{lll}
\hline $\begin{array}{l}\text { Maternal HBeAg } \\
\text { status }\end{array}$ & $\begin{array}{l}\text { Maternal HBV DNA } \\
\text { titer (copies/ml) }\end{array}$ & Vaccine failure rate \\
\hline Positive & $\geq 5 \times 10^{7}$ & $47.9 \%(156 / 326)$ \\
& $<5 \times 10^{7}$ & $36.7 \%(11 / 30)$ \\
\hline Negative & $\geq 5 \times 10^{7}$ & $30.8 \%(4 / 13)$ \\
& $<5 \times 10^{7}$ & $7.0 \%(34 / 485)$ \\
\hline
\end{tabular}

$\geq 5 \times 10^{7}$ copies $/ \mathrm{ml}$ is considered a high level of HBV DNA, $<5$ $\times 10^{7}$ is considered a low level. Data retrieved from the Report of the Korea Centers for Disease Control and Prevention, 2004 [54].

their HBsAg-positive mothers are shown in table 3. Among the 356 neonates born to $\mathrm{HBeAg}$-positive mothers, 167 (46.9\%) were HBsAg positive. Conversely, of the 498 infants born to HBeAg-negative mothers, 39 (7.8\%) were HBsAg positive. Of note is that the data in the table show that irrespective of maternal HBeAg status, more than $30 \%$ of infants born to women with high HBV DNA levels were HBsAg-positive. This study revealed the importance of perinatal transmission of $\mathrm{HBV}$ from $\mathrm{HBeAg}$ positive mothers to their children. In addition, the levels of HBV DNA in carrier mothers are associated with vertical HBV transmission. Song et al. [55] evaluated the failure of HBV immunoprophylaxis in 144 children who received HBIG and the HBV vaccine, and who were born to HBsAg-positive mothers with detectable HBV DNA. Among the 144 participants, 17 (11.8\%) experienced immunoprophylaxis failure. The rates of HBV immunoprophylaxis failure were $12 \%$ among children born to mothers who were $\mathrm{HBsAg}$ positive, $0 \%$ to $\mathrm{HBeAg}$-negative mothers, $21 \%$ to $\mathrm{HBeAg}$-positive mothers, $0 \%$ to mothers 
with undetectable HBV DNA and 27\% to mothers with detectable HBV DNA. Another study by Kang et al. [56] also reported that the failure rate of HBV immunoprophylaxis was $7.4 \%$ and all such cases had been born to HBeAg-positive mothers. According to the 2008 Guidebook for the Hepatitis B Vertical Transmission Prevention Program of the Korean Ministry for Health, Welfare and Family Affairs [36], the rate of anti-HBs among 33,634 subjects who completed the 3 -dose HBV vaccination schedule was $85.1 \%$. Despite adequate HBV vaccination, 1,414 children (4.2\%) experienced immunoprophylaxis failure, defined as HBsAg seropositivity. These reports confirmed again that maternal transmission is the primary reason for vaccine failure and the primary problem that must be addressed. Therefore, maternal HBeAg and HBV DNA levels should be assessed prior to childbirth to identify children at high risk of immunoprophylaxis failure. The effectiveness of strategies to reduce maternal HBV activity during the perinatal period should also be further elucidated.

Another mechanism of vaccine failure involves HBV surface gene mutants. The immune pressure of hepatitis $B$ immunization and HBIG promotes the selection of $\mathrm{HBV}$ surface gene mutants. In particular, S-gene HBV mutants (i.e., the prototype G145R mutation, in which a single amino-acid substitution of glycine to arginine occurs at amino acid 145 of the 'a' determinant of the surface antigen) have been identified in Italy and elsewhere [57-59]. Such mutants can potentially escape neutralizing anti-HBs antibodies and infect vaccinated people. In Taiwan, the prevalence of surface gene mutants was approximately $20 \%$ in HBsAg carrier children [59]. However, the prevalence of HBV surface gene mutants in Korea remains unclear. In Korea, 9 of 31 children (29\%) with perinatal prophylaxis failure had a nucleotide substitution at the 'a' determinant of the surface antigen. However, amino acid substitutions were identified in only 2 cases (6.5\%). In one case, a child was infected by the wildtype virus and a virus that expressed variants of the I126S mutation. In the other case, a child was infected by the wild-type virus and a virus containing the S114A + I126S mutation. Surface gene variants such as G145R were not found in the patients [60]. In another study [61], 2 patients were infected by mutant strains of the virus, with 1 strain containing W74S and F85Y substitutions and the other containing T63I, W74S and T131N substitutions. Neither patient had surface gene variants such as G145R. Therefore, compared with previous studies in other nations, gene surface variants do not appear to play an important role in perinatal immunoprophylaxis failure in Korea.
Inadequate administration of $\mathrm{HBV}$ vaccine may be a cause of perinatal immunoprophylaxis failure. A report by Kim et al. [62] revealed that in $91.9 \%$ of 341 hospitals, HBV vaccination and immunoglobulin injections were performed within $12 \mathrm{~h}$ after birth in more than $90 \%$ of neonates. Furthermore, $84.4 \%$ of the hospitals refrained from administering HBIG to mothers of unknown HBsAg status until a complete report was obtained. Such a delay in providing the initial dose of the vaccine increases the risk of HBV infection in the child. Increasing the HBIG coverage rates among infants born to HBsAg-positive mothers is an important way to prevent mother-to-infant transmission. Data obtained from a 2008 study of the Hepatitis B Vertical Transmission Prevention Program revealed that the second or third dose of the HBV vaccine was administered at appropriate times in only $80 \%$ of infants [43]. Therefore, the rate of vaccination coverage must be increased to minimize the risk of HBV transmission and ensure timely administration of the HBV vaccine. These data suggest that considerable variation exists in the administration of perinatal prophylaxis and that failure to provide appropriate immunoprophylaxis remains an important cause of perinatal HBV infection, especially among infants born to unscreened women.

\section{Conclusion}

Hepatitis B vaccination has effectively reduced the infection and chronicity rates of HBV and related complications. Prior to the introduction of the HBV vaccine, the HBsAg carrier rate among the general Korean population was approximately $8 \%$. Since 1983 , HBV vaccination has been recommended for all neonates in Korea. The overall prevalence of $\mathrm{HBV}$ vaccination has exceeded $99 \%$ since 1990. The HBsAg carrier rate in the general population decreased to $3.7 \%$ in 2007, with a HBsAg carrier rate of $0.44 \%$ among teenagers and of $0.2 \%$ among children younger than 10 years. In addition to the changes in HBV markers that occurred after the introduction of the HBV vaccination program, the $\mathrm{HBV}$ vaccine appears to reduce the risk of HCC. However, acute HBV infection may still occur in unvaccinated and uninfected adults. In those cases, catch-up vaccination will be needed. Despite adequate administration of $\mathrm{HBIG}$ and the $\mathrm{HBV}$ vaccine in children with HBsAg-positive mothers, the vaccine failure rate was $4.2 \%$. No cases of surface gene variants such as G145R have been reported in Korea. Despite considerable effort to reduce HBV infection via the universal vaccination of all newborn and school-age children, a large 
proportion of the population was previously infected with HBV and still harbors the virus.

In conclusion, the prevalence of HBV carriage in Korea was much lower after the introduction of a universal $\mathrm{HBV}$ vaccination program. Korea is now classified as an area of intermediate endemicity for HBV; however, unvaccinated and uninfected adults may require supplemental vaccination to protect against $\mathrm{HBV}$ infection. Despite universal $\mathrm{HBV}$ vaccination, many people are infected with HBV and will become infected in the future. The prevention of complications in infected individuals, such as cirrhosis and hepatocellular carcinoma, requires appropriate therapeutic agents.

\section{Acknowledgment}

This study was supported by a Korea Research Foundation Grant funded by the Korean Government (MOEHRD, Basic Research Promotion Fund), KRF-2007-412-J00303.

\section{Disclosure Statement}

The authors declare that there is no conflict of interest regarding this study.

\section{References}

1 Cha C, Dematteo RP: Molecular mechanisms in hepatocellular carcinoma development. Best Pract Res Clin Gastroenterol 2005; 19:25-37.

2 Ganem D, Prince AM: Hepatitis B virus infection: natural history and clinical consequences. N Engl J Med 2004;350:1118-1129.

-3 Goldstein ST, Zhou F, Hadler SC, Bell BP, Mast EE, Margolis HS: A mathematical model to estimate global hepatitis B disease burden and vaccination impact. Int J Epidemiol 2005;34:1329-1339.

4 Lok AS: Prevention of hepatitis B virus-related hepatocellular carcinoma. Gastroenterology 2004;127:S303-S309.

5 Korea National Statistical Office: Annual statistical report of causes of death in 2005 (in Korean). 2006.

6 Kim SR, Kudo M, Hino O, Han KH, Chung $\mathrm{CH}$, Lee HS: Epidemiology of hepatocellular carcinoma in Japan and Korea. Oncology 2008;75:13-16.

7 Korea National Statistical Office: Annual statistical report of cause of death in 2006 (in Korean). 2007.

8 Han KH, Kim JK: Liver cancer in Korea. Hepatol Res 2007;37:S106-S109.

$\checkmark 9$ Huh K, Choi SY, Whang YS, Lee DS: Prevalence of viral hepatitis markers in Korean patients with hepatocellular carcinoma. J Korean Med Sci 1998;13:306-310.

10 Cho HH, Kim YH, Jung JM, Cho KH, Cho SH, Choi DH, Jeong SH, Lee JH, Han CJ, Kim YC, Lee JO, Kim CM: Clinical characteristics of non-B, non-C hepatocellular carcinoma and detection of HBV, HCV and TTV viremia (in Korean). Korean J Hepatol 2001;7: 439-448.

11 World Health Organization: Expanded programme on immunization. Global Advisory Group. Weekly Epidemiol Rec 1992;3: 11-16.
12 World Health Organization: Statistics on hepatitis B. www.who.int/immunization monitoring/diseases/HepB_coverage.jpg

13 World Health Organization: Vaccines and biologicals: WHO vaccine preventable disease monitoring system: global summary 2009 (data up to 2008). www.who.int/immunization_monitoring/diseases/HepB_map_ schedule.jpg

14 Chen DS: Hepatitis B vaccination: the key towards elimination and eradication of hepatitis B. J Hepatol 2009;50:805-816.

15 Choe BH: The epidemiology and present status of chronic hepatitis B in Korean children (in Korean). Korean J Pediatr 2008;51:696703.

16 Lee $\mathrm{CH}$ : Recommended vaccination schedule against hepatitis A and B. Korean J Med 1998;55:715-723.

17 Korea Institute for Health and Social Affairs: National fertility and family health survey (in Korean). 1994.

18 Lee SY, Choi BY, Shin YJ, Bang KN, Ki M, Park HB, Yoon JD, Lee KC, Youn BJ: A seroepidemiological study on hepatitis B vaccination program in elemantary school students from Kyonggi-do province (in Korean). Korean J Pediatr Infectious Dis 1997;4:240256.

19 Korea Centers for Disease Control and Prevention/Research team for epidemiology: Current state of survey of national immunity (in Korean). 2008.

20 Park JW, Kim BC, Park JH, Kim WY, Koh YI, Rheu D: A survey of positive rates of HBsAg and anti-HBs in a rural area of Korea (in Korean). Korean J Med 1998;55:176-184.

21 Kim SJ, Bom HS, Cho KH, Nam KW, Hong KP, Kim JS: A study for HBsAg and anti-HBs positivities in Chonnam and Cheju provincial officials, 1984 (in Korean). Korean J Med 1986;31:313-317.
22 Chun BY, Lee MK, Rho YK: The prevalence of hepatitis B surface antigen among Koreans by literature review (in Korean). Korean J Epidemiol 1992;14:70-78.

23 Oh EA, Joung NK: A survey of HBs and antiHBs positivities among 173,342 primary, middle and high school students in Kwangju City and Chonnam Province (in Korean). Kor J Gastroenterol 1990;22:825-830.

24 Kim RK, Ahn BM, Lee DS, Lee KM, Park YM, Lee YS, Chung KW, Lee WC, Meng KH: Changes in the positivities of $\mathrm{HBsAg}$ and anti-HCV antibody among army draftees in Korea (in Korean). Korean J Hepatol 2000;6: 474-480.

25 Jang MK, Lee JY, Lee JH, Kim YB, Kim HY, Lee MS, Park CK, Yoo JY: Seroepidemiology of HBV infection in South Korea, 1995 through 1999. Korean J Intern Med 2001;16: 153-159.

26 Jang MK, Lee JY, Lee JH, Kim YB, Kim HY, Yoo JY: The investigation for the change of HBsAg positive rate of grade junior high high-schoolers for recent 3 years in Kangwon province (in Korean). Korean J Med 2000;58:608-615.

27 Korea Centers for Disease Control and Prevention: The Fourth Korea National Health and Nutrition Examination Survey (KNHANES III), 2007. 2008, pp 70-71.

28 Lee DH, Kim JH, Nam JJ, Kim HR, Shin HR: Epidemiological findings of hepatitis B infection based on 1998 National Health and Nutrition Survey in Korea. J Korean Med Sci 2002;17:457-462.

29 Ministry of Education, Science and Technology: 2006 report of the sampling analysis results of students' health examination (in Korean). Yonhap News 2007, pp 9-20.

30 Sim JG, Seo JK, Suh SJ: Prevalence and its changes of hepatitis B viral markers from 1988 to 1993 in Korean children (in Korean). J Korean Pediatr Soc 1995;38:1535-1539. 
31 An YW, Chung EH, Rheem IS: A study of the current (2003-2005) prevalence of anti-HBs and immunologic memory of hepatitis $B$ vaccine in children from the central area of Korea (in Korean). Korean J Pediatr 2006;49: 630-634.

32 Ahn YO, Kim YS, Lee MS, Shin MH: Hepatitis B virus infection rate among Koreans (in Korean). Seoul J Med 1992;33:105-144.

- 33 Song EY, Yun YM, Park MH, Seo DH: Prevalence of occult hepatitis B virus infection in a general adult population in Korea. Intervirology 2009;52:57-62.

- 34 Lee HS, Byun JH, Kim CY: Etiology and outcome of acute viral hepatitis in Korean adults. J Korean Med Sci 1990;5:149-154.

- 35 Jeong SH: Current status and vaccine indication for hepatitis A virus infection in Korea (in Korean). Korean J Gastroenterol 2008;51: 331-337.

36 Ministry for Health, Welfare and Family Affairs/Korea Centers for Disease Control and Prevention: 2008 Guidebook of Hepatitis B Vertical Transmission Prevention Program (in Korean). 2008, pp 6-16.

37 Yim HJ, Chang YJ, Byun KS, Suh YS, Kim JH, Kim JY, Yeon JE, Park JJ, Kim JS, Bak YT, Lee $\mathrm{CH}$ : The changing patterns of acute hepatitis B infection in Korea in the early 2000s (in Korean). Korean J Med 2005;69:601607.

38 Kim IS, Oh HC, Lee Y, Kim JD, Lee WY: Prevalence and changes of HBsAg and anti$\mathrm{HBs}$ for one year period in natural status and after hepatitis B vaccination (in Korean). Korean J Epidemiol 1987;9:40-48.

39 Park BJ, Ahn YO: Cohort study on the asymptomatic chronic carrier rate of hepatitis $B$ virus among male adults in Korea (in Korean). Korean J Epidemiol 1989;11:263-273.

-40 Chang MH, Chen CJ, Lai MS, Hsu HM, Wu TC, Kong MS, Liang DC, Shau WY, Chen DS: Universal hepatitis B vaccination in Taiwan and the incidence of hepatocellular carcinoma in children. N Engl J Med 1997;336: 1855-1859.

-41 Lee MS, Kim DH, Kim H, Lee HS, Kim CY, Park TS, Yoo KY, Park BJ, Ahn YO: Hepatitis $B$ vaccination and reduced risk of primary liver cancer among male adults: a cohort study in Korea. Int J Epidemiol 1998;27:316319 .
42 Seo K, Park SK, Kim YT, Park O: The prevalence of HBsAg positive parturients in Korea (in Korean). Korean J Obstet Gynecol 2005; 48:2119-2124.

43 Korea Centers for Disease Control and Prevention: Communicable Diseases Monthly Report: Hepatitis B Vertical Transmission Prevention Program (in Korean). 2008, p 14.

44 Beasley RP, Hwang LY, Lee GC, Lan CC, Roan CH, Huang FY, Chen CL: Prevention of perinatally transmitted hepatitis $B$ virus infections with hepatitis B immune globulin and hepatitis B vaccine. Lancet 1983;2:10991102 .

45 Stevens CE, Beasley RP, Tsui J, Lee WC: Vertical transmission of hepatitis $B$ antigen in Taiwan. N Engl J Med 1975;292:771-774.

46 Chung WK, Yoo JY, Sun HS, LeeHY, Lee IJ, Kim SM, Prince AM: Prevention of perinatal transmission of hepatitis B virus: a comparison between the efficacy of passive and passive-active immunization in Korea. J Infect Dis 1985; 151:280-286.

47 Kim YJ, Kim SK, Park SH, Yang US, Liu BH: A study on distribution of hepatitis B markers in families of HbsAg-positive blood donors (in Korean). Korean J Med 1983;26: 884-890.

48 Lee JJ, Kim IM: Intrafamilial spread of hepatitis B virus infection (in Korean). Korean J Med 1982;25:1191-1198.

49 Kong H, Kim JH, Cho NY, Kim YH, Jung KM, Yeon JE, Kim JS, Bak YT, Cho KH, Park YK, Byun KS, Lee CH: The hepatitis B carrier rate in siblings of patients with $\mathrm{HBV}$-associated chronic liver disease (in Korean) Korean J Hepatol 2001;7:387-391.

50 Lin HH, Chang MH, Chen DS, Sung JL, Hong KH, Young YC, Yang KH, Lee TY: Early predictor of the efficacy of immunoprophylaxis against perinatal hepatitis B transmission: analysis of prophylaxis failure. Vaccine1991;9:457-460.

51 Ngui SL, Andrews NJ, Underhill GS, Heptonstall J, Teo CG: Failed postnatal immunoprophylaxis for hepatitis $\mathrm{B}$ : characteristics of maternal hepatitis B virus as risk factors. Clin Infect Dis 1998;27:100-106.

52 Ip HM, Lelie PN, Wong VC, Kuhns MC, Reesink HW: Prevention of hepatitis B virus carrier state in infants according to maternal serum levels of HBV DNA. Lancet 1989;1: 406-410.
53 Lee SD, Lo KJ, Wu JC, Tsai YT, Wang JY, Ting LP, Tong MJ: Prevention of maternalinfant hepatitis B virus transmission by immunization: the role of serum hepatitis B virus DNA. Hepatology 1986;6:369-373.

54 Korea Centers for Disease Control and Prevention: Report of the Korea Centers for Disease Control and Prevention (in Korean). 2004, pp 365-367.

55 Song YM, Sung J, Yang S, Choe YH, Chang YS, Park WS: Factors associated with immunoprophylaxis failure against vertical transmission of hepatitis B virus. Eur J Pediatr 2007; 166:813-818

>56 Kang JH, Moon JW, Kong SH, Hwang KS, Mok JS, Lee HJ: Comparison of the seroconversion rate after primary hepatitis B vaccination and after revaccination of non-responders in full-term infants according to mother's HBsAg seropositivity (in Korean). Korean J Pediatr 2008;51:1165-1171.

- 57 Carman WF, Zanetti AR, Karayiannis P, Waters J, Manzillo G, Tanzi E, Zuckerman AJ, Thomas HC: Vaccine-induced escape mutant of hepatitis B virus. Lancet 1990;336: 325-329.

58 Francois G, Kew M, Van Damme P, Mphahlele M J, Meheus A: Mutant hepatitis $B$ viruses: a matter of academic interest only or a problem with far-reaching implications? Vaccine 2001;19:3799-3815.

$>59$ Hsu HY, Chang MH, Ni YH, Lin HH, Wang SM, Chen DS: Surface gene mutants of hepatitis B virus in infants who develop acute or chronic infections despite immunoprophylaxis. Hepatology 1997;26:786-791.

-60 Kim JH, Koh DK, Hur JK, Kang JH, Nainan OV, Margolis HS: The incidence rate of hepatitis B virus surface gene variants in Korean children with immunoprophylaxis failure of perinatal infection (in Korean). Korean J Hepatol 2005; 11:320-328.

61 Lee KM, Kim YS, Ko YY, Yoo BM, Lee KJ, Kim JH, Hahm KB, Cho SW: Emergence of vaccine-induced escape mutant of hepatitis $B$ virus with multiple surface gene mutations in a Korean child. J Korean Med Sci 2001;16: 359-362.

62 Kim B, Seo K, Park S, Kim Y, Park O, Lee HJ, Hong WK, Whang HS: Evaluation of prevention program for neonatal vertical transmission from HBsAg positive mother in Korea (in Korean). Korean J Obstet Gynecol 2005; 48:2067-2072. 